Meanwhile, surveys at the other two plants and the Monju reactor are set to begin this year. But critics are questioning the group's methods.

Okumura says that some of what Shimazaki's experts are citing as active faults could well be the result of landslides. He says the group lacks specialists on rocks and sediments - a limitation that the NRA says it has addressed by consulting the relevant experts.
Others are concerned that the group has been too quick to conclude that the fractures they have identified are dangerous. "There are fractures everywhere you look," says Haruo Yamazaki, a seismotectonics researcher at Tokyo Metropolitan University. He says the debate should focus on what, if any, damage the reactors would suffer if the faults moved.

Shimazaki says that the NRA will weigh up the plants' vulnerability to earthquake damage as it evaluates the seismology reports. But the plants will face more hurdles if regulations being drafted by the NRA become law without changes. Due to take effect in July, new requirements for vents and radiation filters could mean that the Oi reactors would have to be shut down immediately and others could not restart without modifications.

\title{
Alert over South Korea toxic leaks
}

\section{Government moves to tighten oversight after string of hydrogen fluoride accidents.}

\section{BY SOO BIN PARK IN GUMI, SOUTH KOREA}

$\mathrm{B}$ y mid-December, the chill winter winds had stripped South Korea's trees bare. But around the city of Gumi, about 280 kilometres south of Seoul, blighted branches still bore a shroud of brown, withered leaves - reminders of the chemical accident that shook the region some three months earlier. At the edges of arable fields, red placards waved in the breeze: "Contaminated by the hydrofluoric acid leak," they warned. "Not edible."

On 27 September 2012, about eight tonnes of highly toxic hydrogen fluoride (HF) gas, which dissolves in the moisture in air to form droplets of corrosive hydrofluoric acid, burst from the Hube Global chemical plant in Gumi. The leak killed five workers and injured at least 18 others, including plant employees and emergency personnel.

Thousands of local citizens say that inhaling the acid has damaged their health. Exposure to HF can trigger an irregular heartbeat and cause fluid buildup in the lungs, and the long-term health effects include chronic lung disease. The government has said that it will pay about 36.4 billion won (US\$33.4 million) in compensation to citizens and local businesses.

This may sound like a freak accident but it was not. On 15 January, about 2,500 litres of hydrofluoric acid escaped at a factory in Cheongju, injuring one person. And on 28 January, a worker died during a hydrofluoric acid leak at a Samsung Electronics computer-chip plant in Hwaseong. In the wake of the incidents, experts are raising questions about safety in the country's research-intensive chemical and microelectronics industries, and the government is investigating what went wrong.

"South Korea tends to focus on resolving accidents only when death occurs, but action to prevent such accidents is still severely lacking," says Lim Hyun-Sul, a researcher in preventive medicine at Dongguk University in Gyeongju. Lim, who has been treating patients for HF exposure since the 1990s, says that preparation is key. "Protocols must be pre-

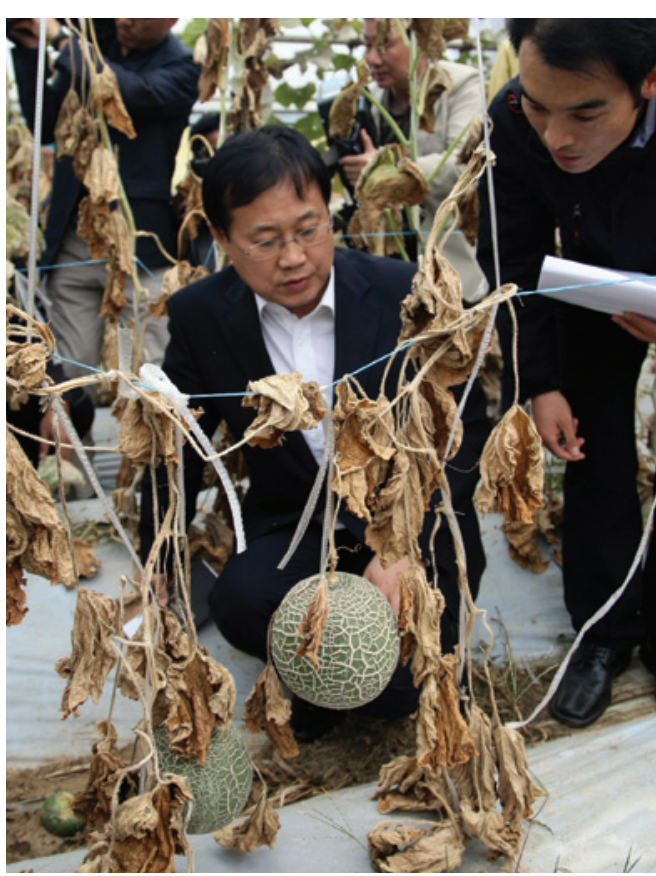

Government investigators survey the impact of a hydrogen fluoride leak.

pared thoroughly in advance, including education of factory workers, firefighters, medical doctors and public servants about the risks of toxic chemicals."

\section{HANDLE WITH CARE}

Hydrofluoric acid is commonly used by the electronics industry to etch patterns into silicon chips, and as South Korea has become one of the world's leading electronics exporters in recent years, annual consumption of HF has risen sharply. According to the Ministry of Environment, 26 businesses each handled around 10 tonnes of HF in 2001; by 2010, the number of these large-scale handlers had almost tripled, and in 2011, 545 companies were registered as producers or distributors of the gas.

A mistake by Hube Global workers may have caused the Gumi disaster. Surveillance-camera footage seen by Nature shows two workers attempting to connect a hose to a valve on top of a HF tank. Neither is wearing protective gear. Suddenly, white vapour gushes from the tank, engulfing the workers and killing them instantly. Prosecutors have indicted three Hube Global executives on suspicion of negligence resulting in death, citing the absence of proper safety equipment and a lax attitude to safety regulations.

The disaster was compounded by the regional government's response. "Both the immediate and the long-term response to the hydrofluoric acid release from the South Korean government seemed to be really chaotic and uncontrolled," says Neal Langerman, who runs the consulting company Advanced Chemical Safety, based in San Diego, California.

Some firefighters failed to use chemicalprotective clothing and self-contained breathing apparatus because they did not initially understand the threat posed by HF. Almost a day passed before they began using calcium hydroxide to neutralize the acid, which is standard procedure after such a leak.

Meanwhile, residents nearby were exposed to HF for about four hours before local authorities decided to evacuate them. The following day, they were told to return after investigators found no HF in the air. But thousands of residents soon complained of nausea, chest pains and rashes, suggesting that the all-clear had been sounded too early. Eleven days after the accident, the national government designated the area a 'special disaster zone', and residents began to leave again.

Evacuated residents finally returned 
to their homes in late December, after investigators reported that hydrofluoric acid concentrations had dropped to safe levels. Officials have allowed farming to resume, and work has restarted at Hube Global. But some experts worry that residents should stay away until there has been a more rigorous assessment of safety at the plant. "Three months is not sufficient time for thorough investigations of this incident," says Langerman.

Lim adds that long-term monitoring of air and water is essential. "Once underground water gets tainted, there is a possibility that fresh water could become polluted," he says. A stream that lies just 1.5 kilometres from the Hube Global plant flows into the Nakdong River, which supplies water to more than 10 million people in the surrounding area.

So far, more than 12,000 people have claimed compensation for their injuries, and Woo Kuck Hyeun, an occupational and environmental physician at Soon Chun Hyang University Hospital in Gumi, is leading a follow-up study of those exposed to the gas. "It's almost an unprecedented case, so we are facing a lot of trial and error," he says.

Woo explains that the survey is modelled on a two-year health investigation that followed a 1987 leak at an oil refinery in Texas, when 18 tonnes of HF were released (H. H. Dayal et al. Ann. Epidemiol. $2,213-230 ; 1992)$. In contrast to the accident at Gumi, however, the authorities there acted quickly to contain the leak. Within seven minutes of the release, water was used to contain and hydrate the escaping gas; within 20 minutes, a 0.8-kilometre evacuation zone was established.

The response to the Gumi accident has already been the subject of a parliamentary inquiry, and South Korea's government has promised to establish a centre that will work with local branches of the environment ministry to oversee the use of dangerous chemicals. Lim says that the regional approach is an important step. "Most chemical plants are located out of Seoul, so it's too late to wait for government agents coming from the capital to deal with an accident."

Meanwhile, the clean-up near Gumi continues. On 13 December, the government began burning about 9,100 tonnes of crops and trees killed by the gas, leaving the scene of the accident even more barren than before. "Surrounded by thousands of blighted trees, and watching them every day, recreated the trauma," says Kim Sangho, an elementary-school teacher, explaining why he has not yet returned to his home. "It's nothing different from the Fukushima accident," he adds. "What kind of people would buy the agricultural products from my village even if the government says they are absolutely safe?"

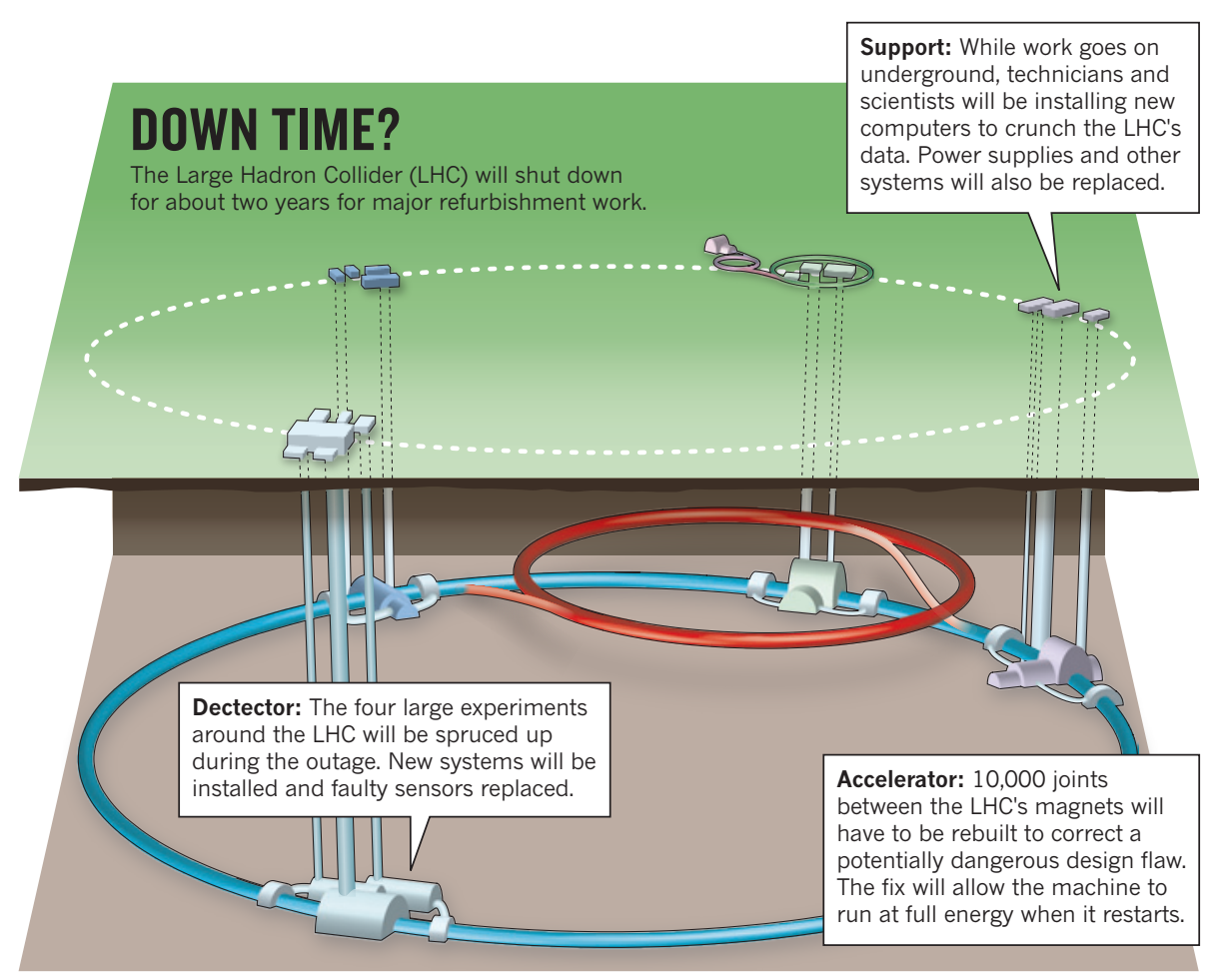

PARTICLE PHYSICS

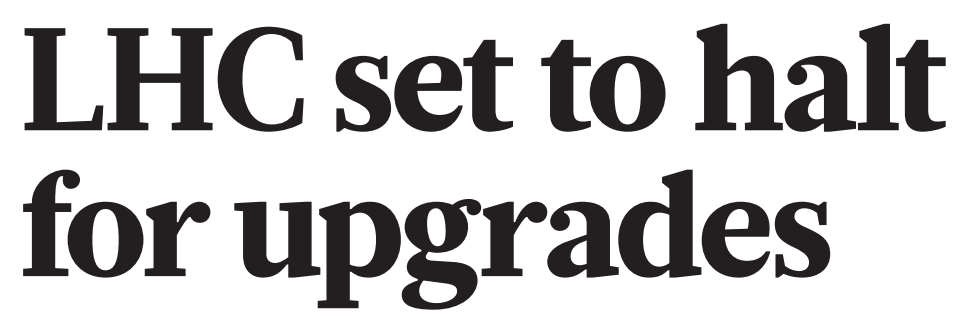

Maintenance, improvement work and data analysis will
keep scientists busy as collider's planned closure begins.

\section{BY GEOFF BRUMFIEL}

$\mathrm{W}$ ith the discovery of the Higgs boson or something very like it under its belt, the world's most powerful particle collider is ready to take a well-earned rest. The Large Hadron Collider (LHC) will shut down on 11 February ahead of around two years of upgrade work.

The break, known as LS1 for 'long stop one', is needed to correct several flaws in the original design of the collider, which is located underground at CERN, Europe's particlephysics laboratory near Geneva in Switzerland. The fixes will allow the collider to almost double the energy at which it smashes protons together.

But there will be no long holiday for the thousands of physicists who depend on the LHC for their data. A bruising schedule of maintenance, upgrades and forward planning will keep the scientists who work on the collider's detectors busy (see 'Down time?'). Meanwhile, graduate students and postdocs will be poring over the past three years' worth of data, refining their measurements of the Higgs-like particle discovered last summer and searching for any unusual signals. "It's absolutely not time off," says Dave Charlton, the deputy spokesman for ATLAS, the largest detector at the LHC.

The LHC's spectacular run got off to a shaky start in 2008. Shortly after operators fired it up, a single bad electrical connection caused coolant to vaporize, triggering an explosion that damaged an entire sector of the machine (see Nature 455, 436-437; 2008). Repairs took more than a year, and a subsequent review revealed potentially dangerous flaws in the original design, according to Steve Myers, CERN's director for accelerators. The worst lay in a system of copper bars designed to draw current away from delicate superconducting cables in the event of an emergency shutdown or failure. The way in which the bars had been installed made them vulnerable to failure, Myers says.

To protect the machine from further disaster, the accelerator team made the decision to run the collider at half power until all 10,000 copper connections could be repaired and 